\title{
Robust Controller Design for a Synchronous Reluctance Drive
}

\author{
Ming-Tsan Lin and Tian-Hua Liu \\ Department of Electrical Engineering \\ National Taiwan University of Science and Technology \\ Taipei, Taiwan 106 \\ R. O. C.
}

\begin{abstract}
This paper presents a systematic robust controller design for a synchronous reluctance drive system. Based on a simplified model of the system, a robust position controller has been derived. A digital signal processor, TMS-320-C30, is used to implement the control algorithm. Furthermore, all the current, velocity, and position control loops are executed by the digital signal processor. The system, as a result, is very flexible. Although the hardware circuit of the system is very simple, the synchronous reluctance drive system can accurately control a one-axis table. In addition, the system also has good transient response, load disturbance response, and tracking ability. Several experimental results validate the theoretical analysis.
\end{abstract}

\section{INTRODUCTION}

The synchronous reluctance motor (SRM) has been recognized to have many advantages. For example, its structure is rugged and simple. In addition, its rotor does not have any winding or magnetic material. The SRM, therefore, is easy to manufacture. Prior to ten years ago, the SRM was regarded as inferior to other types of ac machines due to its lower average torque and larger torque pulsation. Recently, however, researchers have proposed many methods to improve the characteristics of the motor as well as the drive system [1]-[2]. The SRM has been shown to be suitable for ac drive systems for several reasons. First, it is not necessary to compute the slip of the SRM as it is with the induction motor. As a result, there is no parameter sensitivity problem. Next, it does not require any permanent magnetic material as the permanent magnet synchronous motor does. Many researchers have applied vector control to the SRMs. These studies, however, used only proportional-integral (PI) controllers. To obtain a high performance drive system, the

The National Science Council of R. O. C. supported this work under grant NSC87-2213-E-011-054 controller design is very important; however, there are only a few papers, which have studied this topic. For example, Liu, et al. proposed a fuzzy sliding-mode controller design for a SRM drive [3]. With this system, however, it is necessary to estimate the acceleration of the motor. Moreover, only a speed-loop controller is designed to achieve both a fast transient response and a good load disturbance response. The fuzzy sliding-mode control algorithm, therefore, is very complicated and is difficult to implement. In this paper, an advanced $H^{\infty}$ controller to improve the transient response and load -disturbance response of the system has been proposed. The design procedures of the control algorithm are complicated; however, the implementation of the control law is very simple. In addition, the closed-loop SRM drive system performs well by using this proposed control method. A one-axis precision table is driven by the proposed SRM drive system. The whole system performs well. For example, it has a fast response and a good load disturbance rejection capability. The steady-state position error is \pm 1 bit. In addition, the position control system has good tracking ability. It can track a time varying command well. To the best of the authors' knowledge, this is a new control algorithm to drive the SRM. Moreover, this is the first time the SRM drive system has been applied in an industrial position control. The SRM was not applied in industrial position control due to its high torque pulsation. This paper first uses an SRM drive to control an industrial one-axis precision position control. The experimental results show that an SRM drive can be successfully applied in industrial position control with satisfactory performance.

\section{MATHEMATICAL MODEL}

\section{A. System Description}

The block diagram of the SRM drive system is shown in Fig. 1. The system includes four major parts: the motor, the 
inverter, the sensors, and the digital signal processor.

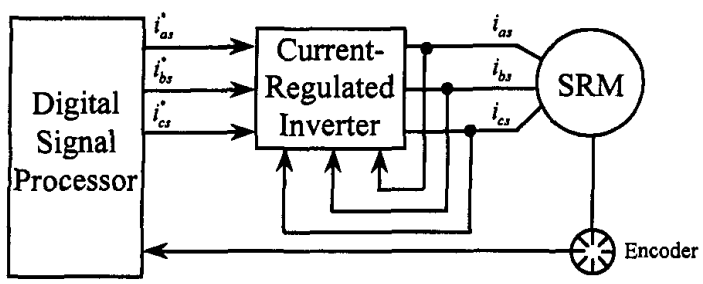

Fig. 1 Block Diagram of Drive System

\section{B. Motor and Load Dynamics}

The mathematical model of an SRM without damping winding can be described, in the synchronous $d^{e}-q^{e}$ reference frame, by the following nonlinear differential equations:

$$
\begin{aligned}
& \mathrm{p} i_{d s}=\left(v_{d s}-r_{s} i_{d s}+\omega_{r} L_{q s} i_{q s}\right) / L_{d s} \\
& \mathrm{p} i_{q s}=\left(v_{q s}-r_{s} i_{q s}-\omega_{r} L_{d s} i_{d s}\right) / L_{q s}
\end{aligned}
$$

where $\mathrm{p}$ is the differential operator $\mathrm{d} / \mathrm{dt}, i_{d s}$ and $i_{q s}$ are the $d^{e}-q^{e}$ axis stator currents, $v_{d s}$ and $v_{q s}$ are the $d^{e}$. $q^{e}$ axis stator voltages, $r_{s}$ is the stator resistance, $\omega_{r}$ is the electrical speed of the rotor shaft, and $L_{d s}$ and $L_{q s}$ are the $d^{e}-q^{e}$ axis stator inductances. The electromagnetic torque of the motor is

$$
T_{e}=\frac{3}{2} \frac{P_{0}}{2}\left(L_{d s}-L_{q s}\right) i_{d s} i_{q s}
$$

where $P_{0}$ is the number of poles of the motor. The speed of the motor is

$$
\begin{aligned}
& \mathrm{p} \omega_{r}=\frac{1}{J}\left(T_{e}-T_{l}-\mathrm{B} \omega_{r}\right) \\
& \mathrm{p} \theta_{r}=\omega_{r}
\end{aligned}
$$

where $J$ is the inertia constant of the motor and load, $T_{l}$ is the external load torque, $B$ is the viscous frictional coefficient of the motor and load, and $\theta_{r}$ is the shaft position of the motor. The main purpose of this paper is to develop a high performance controller for an SRM drive. As a result, this paper focuses on the position-loop controller design. In order to reduce the required computing time of the DSP, a simple three-phase independent currentregulated control method is used here. The current control is executed by the DSP with a $50 \mu$ sampling interval. The switching frequency of the inverter, therefore, is $20 \mathrm{kHz}$. Then, the three phase currents $i_{a s}, i_{b s}, i_{c s}$ can follow the three-phase current commands $i_{a s}^{*}, i_{b s}^{*}, i_{c s}^{*}$. After the coordinate transformation from the $a-b-c$ stationery frame to the $d^{e}-q^{e}$ synchronous frame, we can conclude that the $d^{e}-q^{e}$ axis currents $i_{d s}$ and $i_{q s}$ follow the $d^{e}-q^{e}$ axis current commands $i_{d s}^{*}$ and $i_{q s}^{*}$ very well. The torque command (idea torque), therefore, can be expressed as

$$
T_{e}^{*}=\frac{3}{2} \frac{P_{0}}{2}\left(L_{d s}-L_{q s}\right) i_{d s}^{*} i_{q s}^{*}==K_{i} i_{q s}^{*}
$$

where $T_{e}^{*}$ is the torque command, $i_{d s}^{*}$ is the d-axis current command, $K_{i}$ is the torque constant, and $i_{q s}^{*}$ is the q-axis current command.

\section{CONTROL ALGORITHM}

Fig. 2 shows the block diagram of the SRM control system. The $\mathrm{H}^{\infty}$ state-feedback controller is design as following steps. First, letting $X_{1}=\omega$, and $X_{2}=\theta_{r}$, we can obtain the dynamic equations:

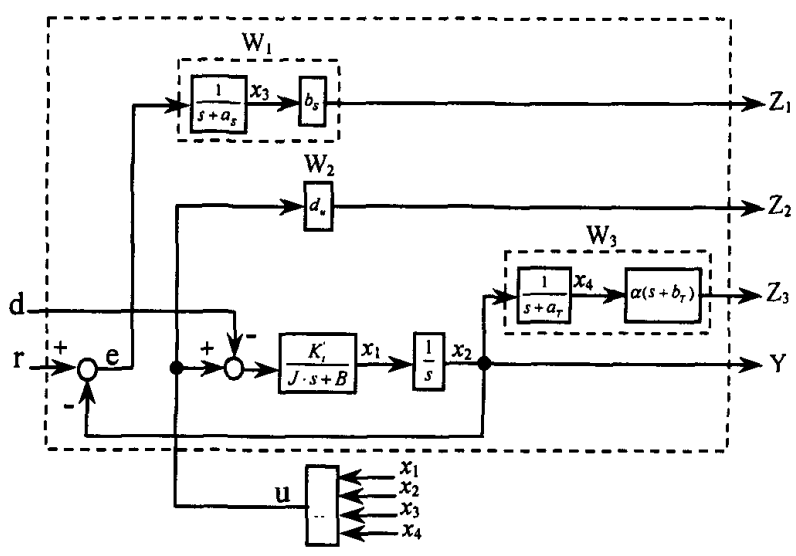

Fig. 2 The block diagram of control system

$$
\begin{aligned}
& {\left[\begin{array}{l}
\dot{x}_{1} \\
\dot{x}_{2} \\
\dot{x}_{3} \\
\dot{x}_{4}
\end{array}\right]=\left[\begin{array}{cccc}
-\frac{B}{J} & 0 & 0 & 0 \\
1 & 0 & 0 & 0 \\
0 & -1 & -a_{s} & 0 \\
0 & 1 & 0 & -a_{T}
\end{array}\right]\left[\begin{array}{l}
x_{1} \\
x_{2} \\
x_{3} \\
x_{4}
\end{array}\right]+} \\
& {\left[\begin{array}{cc}
0 & -\frac{K_{1}}{J} \\
0 & 0 \\
1 & 0 \\
0 & 0
\end{array}\right]\left[\begin{array}{l}
r \\
d
\end{array}\right]+\left[\begin{array}{c}
\frac{K_{1}}{J} \\
0 \\
0 \\
0
\end{array}\right] u}
\end{aligned}
$$




$$
\begin{aligned}
& {\left[\begin{array}{l}
Z_{1} \\
Z_{2} \\
Z_{3}
\end{array}\right]=\left[\begin{array}{cccc}
0 & 0 & b_{s} & 0 \\
0 & 0 & 0 & 0 \\
0 & \alpha & 0 & \alpha\left(b_{T}-a_{T}\right)
\end{array}\right]\left[\begin{array}{l}
x_{1} \\
x_{2} \\
x_{3} \\
x_{4}
\end{array}\right]+} \\
& {\left[\begin{array}{ll}
0 & 0 \\
0 & 0 \\
0 & 0
\end{array}\right]\left[\begin{array}{l}
r \\
d
\end{array}\right]+\left[\begin{array}{c}
0 \\
d_{u} \\
0
\end{array}\right] u} \\
& e=\left[\begin{array}{llll}
0 & -1 & 0 & 0
\end{array}\right]\left[\begin{array}{l}
x_{1} \\
x_{2} \\
x_{3} \\
x_{4}
\end{array}\right]+\left[\begin{array}{ll}
1 & 0
\end{array}\right]\left[\begin{array}{l}
r \\
d
\end{array}\right]
\end{aligned}
$$

and

$$
\begin{aligned}
& A=\left[\begin{array}{cccc}
-\frac{B}{J} & 0 & 0 & 0 \\
1 & 0 & 0 & 0 \\
0 & -1 & -a_{s} & 0 \\
0 & 1 & 0 & -a_{T}
\end{array}\right], \\
& B_{1}=\left[\begin{array}{cc}
0 & -\frac{K_{i}^{\prime}}{J} \\
0 & 0 \\
1 & 0 \\
0 & 0
\end{array}\right], B_{2}=\left[\begin{array}{c}
\frac{K_{i}}{J} \\
0 \\
0 \\
0
\end{array}\right] \text {, } \\
& C_{1}=\left[\begin{array}{cccc}
0 & 0 & b_{s} & 0 \\
0 & 0 & 0 & 0 \\
0 & \alpha & 0 & \alpha\left(b_{T}-a_{T}\right)
\end{array}\right] \text {, } \\
& D_{12}=\left[\begin{array}{c}
0 \\
d_{u} \\
0
\end{array}\right], w=\left[\begin{array}{l}
r \\
d
\end{array}\right], \\
& C_{2}=\left[\begin{array}{llll}
0 & -1 & 0 & 0
\end{array}\right], D_{21}=\left[\begin{array}{ll}
1 & 0
\end{array}\right] \text {, }
\end{aligned}
$$

where $A_{1}, B_{1}, B_{2}, C_{1}, C_{2}, D_{12}$, and $D_{21}$ are relative matrices or vectors of the dynamic equations. The $x_{1}$ to $x_{4}$ are state variables, $Z_{1}$ to $Z_{3}$ are the weighted states, $r$ is the reference input, $d$ is the external disturbance, $u$ is the control input, and $a_{\mathrm{s}}, b_{\mathrm{s}}, a_{\mathrm{T}}, b_{\mathrm{T}}, d_{\mathrm{u}}$, and $\alpha$ are the parameters of the weighted functions. Then, we can define the performance index as [4]

$$
\zeta=\int_{0}^{\infty}\left(Z^{T} Z-\beta^{2} w^{T} w\right) d t
$$

where $\zeta$ is the performance index, and $\beta$ is a constant which is assigned by the designer. Then, after some mathematical processes, we can derive

$$
\begin{aligned}
u^{*} & =-\left[\left(D_{12}^{T} D_{12}\right)^{-1} D_{12}^{T} C_{1}+\left(D_{12}^{T} D_{12}\right)^{-1} B_{2}^{T} P\right] x \\
& =-k_{\infty} X
\end{aligned}
$$

where $u^{*}$ is the optimal control input, and $k_{\infty}$ is the $H^{\infty}$ feedback gain. The matrix $P$ is obtained by solving the following Riccati equation,

$$
\begin{aligned}
& 0=P\left(A-B_{2}\left(D_{12}^{T} D_{12}\right)^{-1} D_{12}^{T} C_{1}\right)+\left(A-B_{2}\left(D_{12}^{T} D_{12}\right)^{-1} D_{12}^{T} C_{1}\right) P^{T}+ \\
& P\left(\frac{1}{\gamma^{2}} B_{1} B_{1}^{T}-B_{2}\left(D_{12}^{T} D_{12}\right)^{-1} B_{2}^{T}\right) P+C_{1}^{T}\left(I-D_{12}^{T}\left(D_{12}^{T} D_{12}\right)^{-1} D_{12}^{T}\right) C_{1}
\end{aligned}
$$

\section{EXPERIMENTAL RESULTS}

\section{A. Implementation}

The block diagram of the implemented drive system is shown in Fig. 1. The system consists of four major parts: a DSP system, an inverter, an SRM, and some sensors. A TMS-320-C30 DSP system is used here. The DSP system executes the control algorithm, the $d-q$ axis to $a-b-c$ axis coordinate transformation, and the current regulated PWM switching algorithm. Finally, the DSP determines the firing signals and send them to the inverter. A closed-loop system is thus achieved. The three-phase current deviations of the motor are small because the DSP can finish executing the current-regulated algorithm in only $50 \mu \mathrm{s}$. In addition, the DSP finishes executing the position-loop control in $1 \mathrm{~ms}$. Because most of the jobs are implemented by software, the hardware circuit, therefore, is very simple. The inverter is realized by using six insulated gate bipolar transistors (IGBTs). The motor is a 3 -phase, 4 pole, $220 \mathrm{~V}, 0.75 \mathrm{HP}$ $\mathrm{SRM}$, with $1800 \mathrm{r} / \mathrm{min}$ rated speed, manufactured by the Reliance Electric Company. The parameters of the motor are shown in Table I. The IGBTs have the following specifications: $50 \mathrm{~A}$ continuous rating current, $100 \mathrm{~A}$ maximum peak current, and $1200 \mathrm{~V}$ rating voltage. The sensor of the system includes two parts: the Hall-effect current sensors and the encoder. The Hall-effect sensors are type LP-100P, made by LEM Company. The bandwidth of the Hall-effect sensors is about $100 \mathrm{kHz}$. The DSP reads the output signals of the Hall-effect sensors via analog-to-digital (A/D) converters. The A/D converters are 12 bit, with $3 \mu \mathrm{s}$ conversion time. The encoder originally outputs 2000 position pulses with one index pulse for every mechanical 
revolution. However, it can output 8000 pulses with an index pulse by using a multiplier circuit.

\section{TABLE I}

Parameters of the Motor

$\begin{array}{ll}r_{s} & 2 \Omega \\ L_{d s} & 0.138 \mathrm{H} \\ L_{q s} & 0.0572 \mathrm{H} \\ J & 0.002394 \mathrm{~N} \cdot \mathrm{m} / \mathrm{s}^{2} \\ & \\ \text { (with one-axis moving table) } & \\ J_{L} & 0.00512 \mathrm{~N} \cdot \mathrm{m} / \mathrm{s}^{2} \\ \text { (with one-axis table and external inertia) }\end{array}$

\section{B. Experimental Results}

Some experimental results are shown here. Fig. 3 shows the responses of position control for the one-axis table with short distance moving. Fig. 3(a) is the position response. Fig. 3(b) is the relative velocity response. Fig. 3 (c) is its relative q-axis current. Fig. 4 shows the responses of the table with an external inertia. Fig. 5 shows the responses of the table with a long distance moving. Fig. 6 shows the tracking responses. Fig. $6(\mathrm{a})$ is the position response. Fig. $6(\mathrm{~b})$ is its relative velocity response. Fig. 6 (c) is its q-axis current. Fig. 7 is the line voltage of the motor.

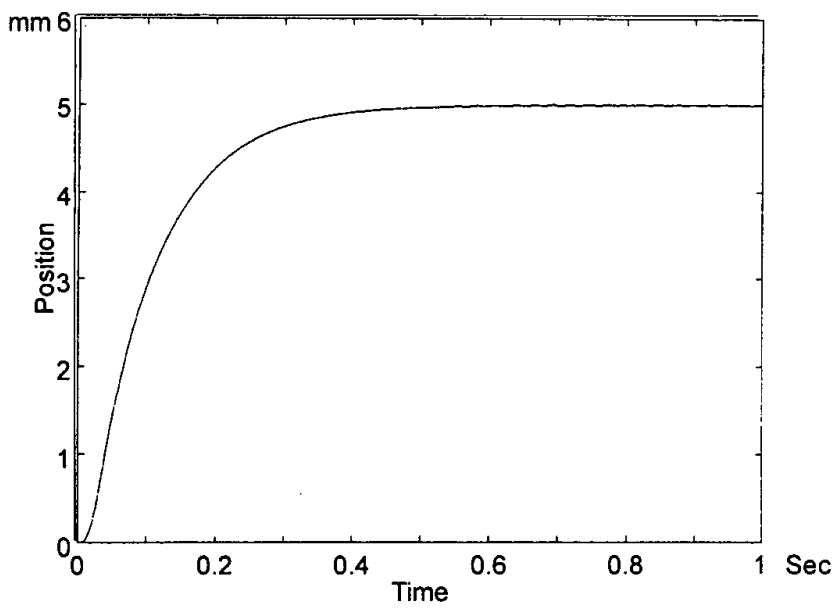

(a)

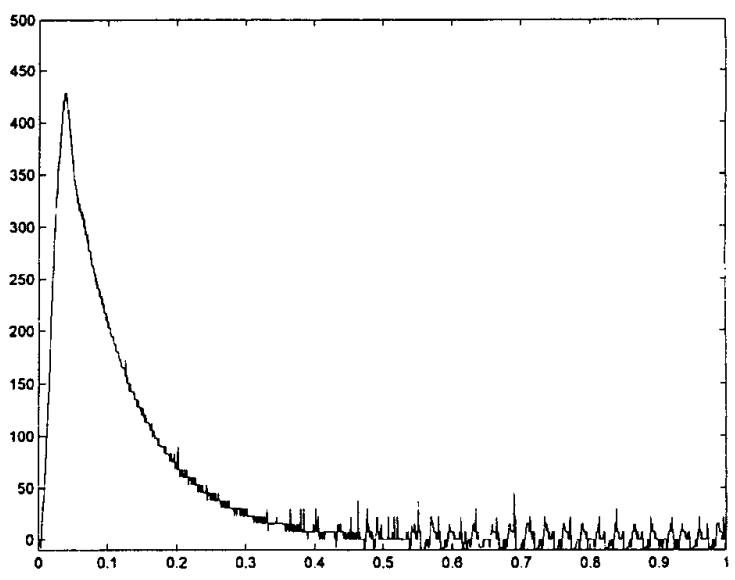

(b)

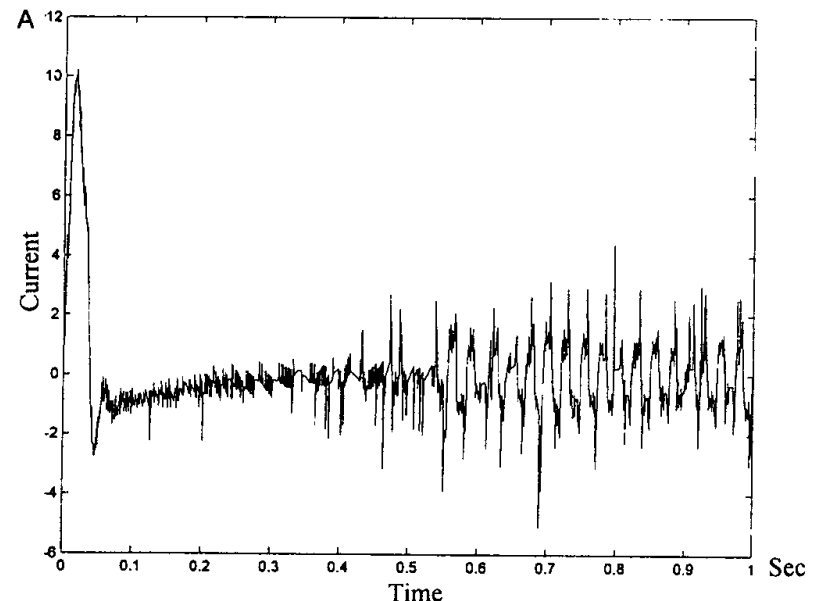

(c)

Fig. 3 Position control $(5 \mathrm{~mm})$ with moving table (a) position (b) velocity (c) current.

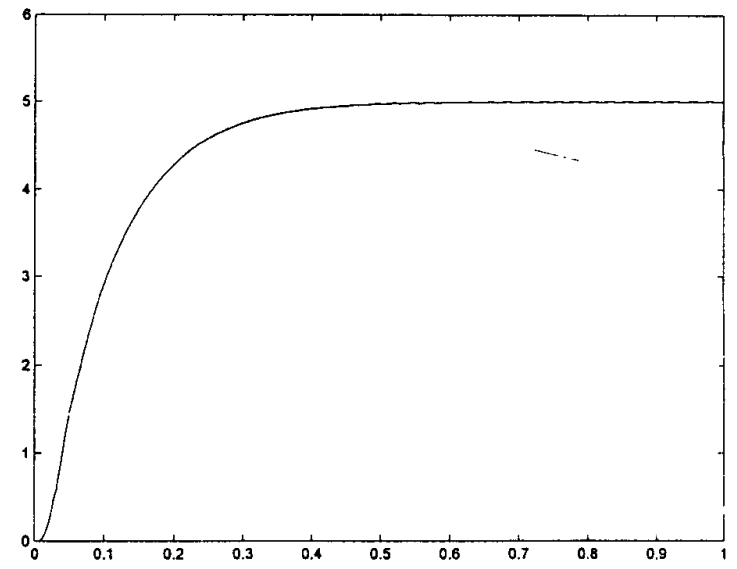

(a) 


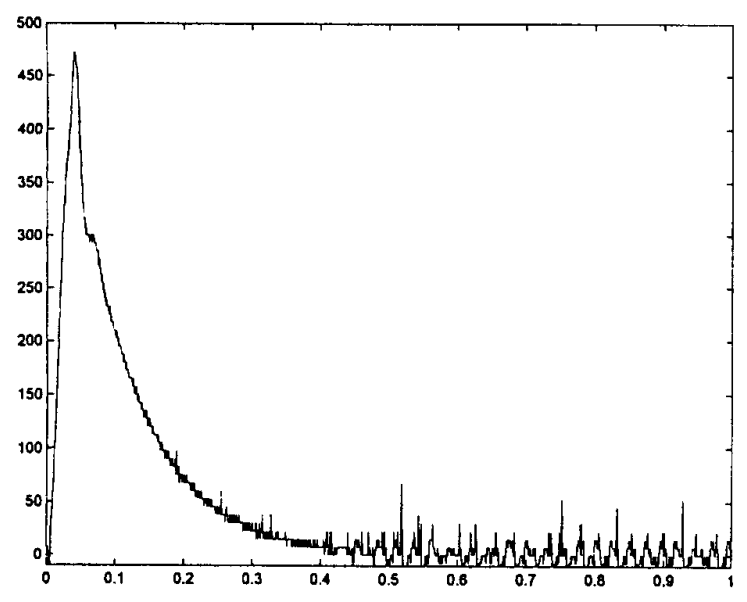

(b)

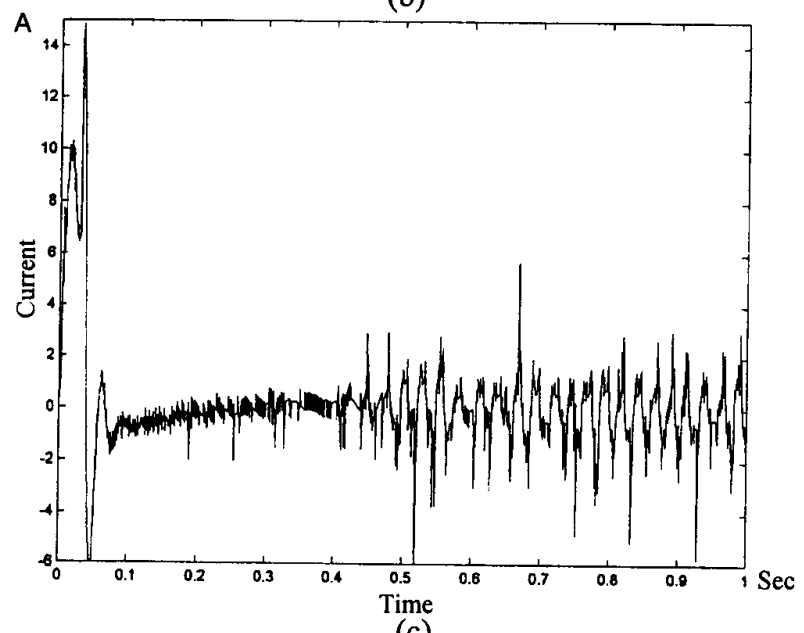

Fig. 4 Position control $(5 \mathrm{~mm})$ with moving table and external inertia (a) position (b) velocity (c) current.

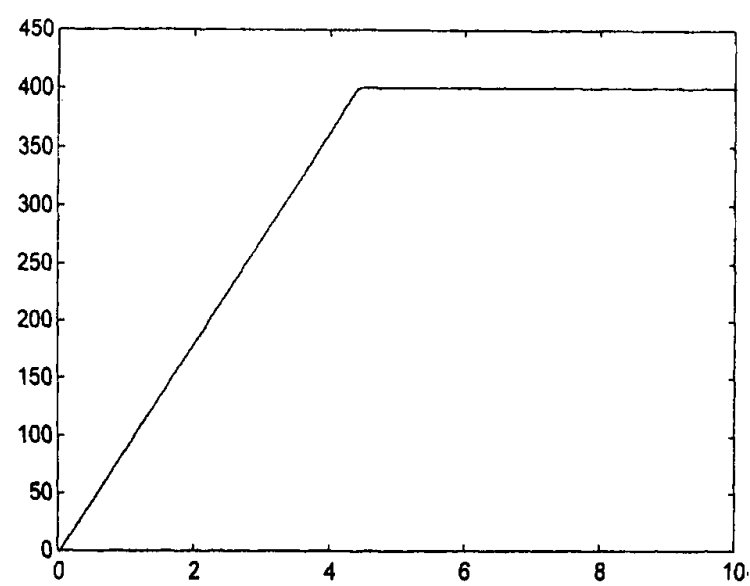

(a)

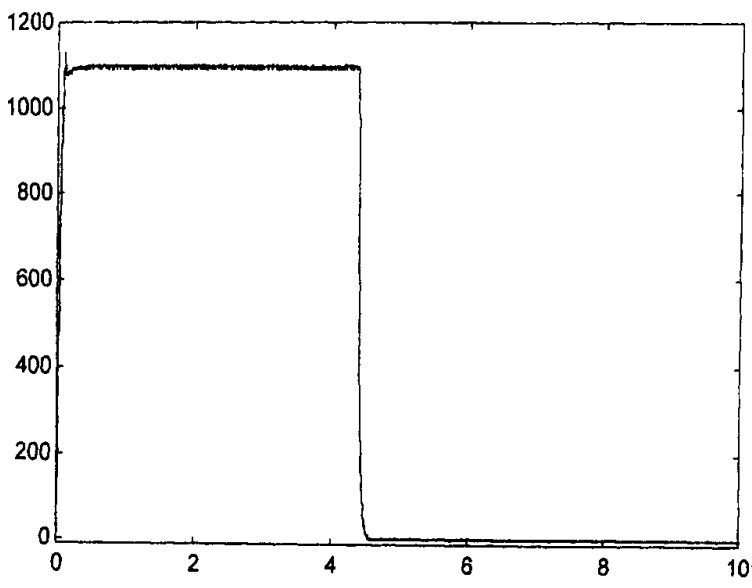

(b)

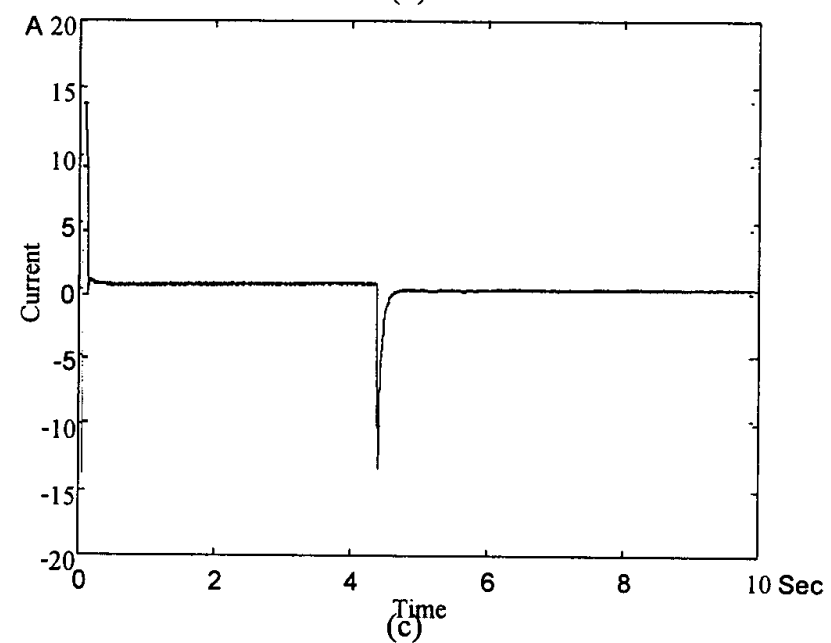

Fig. 5 Position control with external inertia $(400 \mathrm{~mm})$

(a) position (b) velocity (c) current.

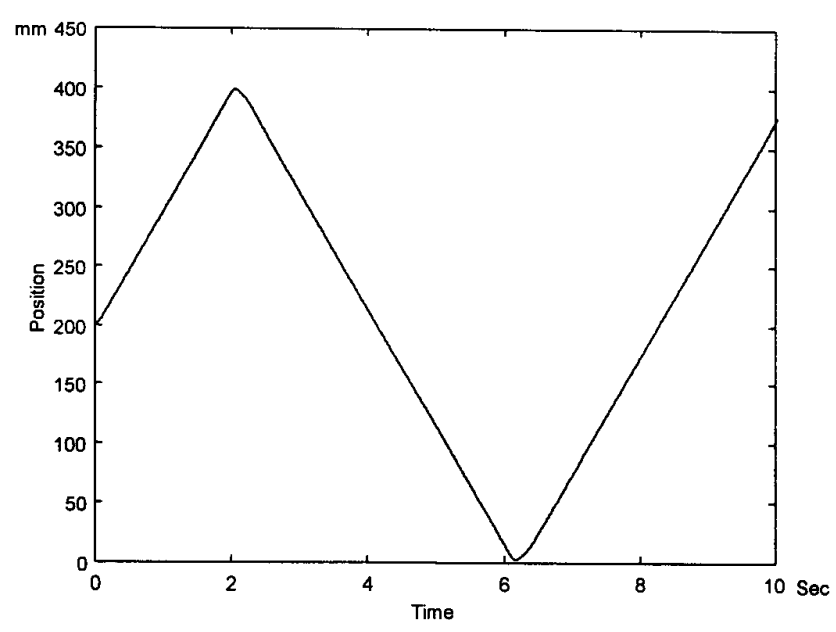

(a) 


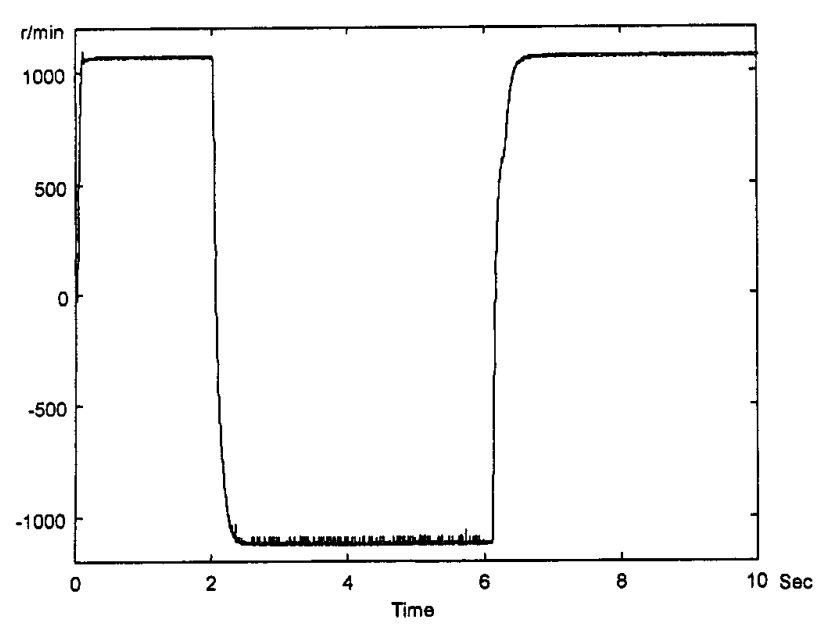

(b)

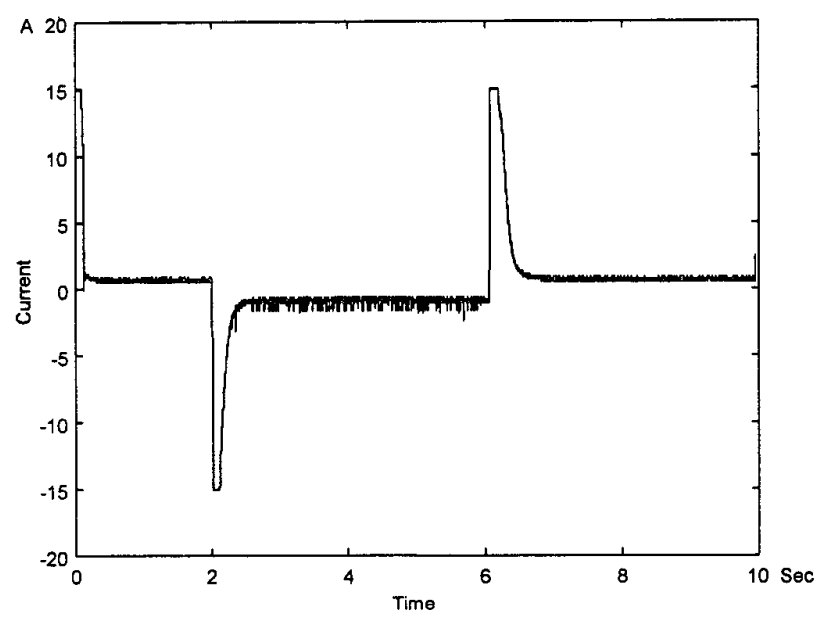

(c)

Fig. 6 The position tracking responses

(a) position (b) velocity (c) current.

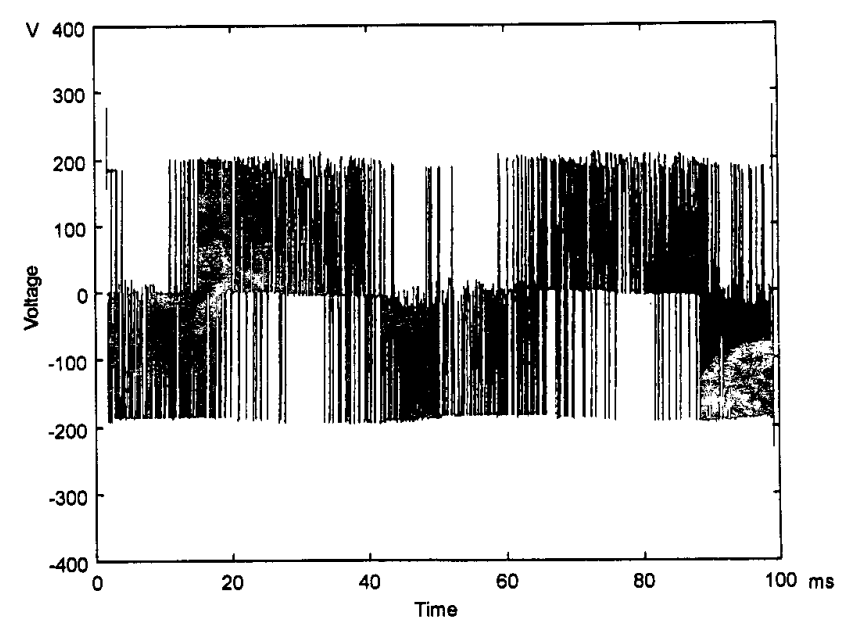

Fig. The PWM voltage of the SRM.

\section{Conclusions}

This paper proposes the $H^{\infty}$ controller design for a fully digital synchronous reluctance drive. The experimental results show that the whole drive system has good transient response, load disturbance response, and tracking ability. This paper proposes a new direction to design and implement a new position control algorithm for the synchronous reluctance drive.

\section{References}

[1] L. Xu, X. Xu, T. A. Lipo, and D. W. Novotny, "Vector control of a synchronous reluctance motor including saturation and iron loss," IEEE Trans. Ind. Appl., vol. 27, no. 5, pp. 977-985, Sep./Oct. 1991.

[2] R. Lagerquist, I. Boldea, and T. J. E. Miller, "Sensorless control of the synchronous reluctance motor," IEEE Trans. Ind. Appl., vol. 30, no. 3, pp. 673-682, May/June 1994.

[3] T. H. Liu and M. T. Lin, "A fuzzy sliding-mode controller design for a synchronous reluctance motor drive," IEEE Trans. Aero. and Electro. Syst., vol. 32, no. 3, pp. 1065-1076, July 1996.

[4] K. Zhou, J. C. Doyle, and K. Glover, "Robust and optimal control," Prentice Hall, 1996 